The golden mean: A systems biology approach to language disorders

Antonio Benítez Burraco

Área de Lingüística General. Departamento de Lengua Española, Lingüística y Teoría de la Literatura. Facultad de Filología. Universidad de Sevilla

C/ Palos de la Frontera s/n

41004-Sevilla (España)

e-mail: abenitez8@us.es

The golden mean: A systems biology approach to language disorders

ABSTRACT: Current clinical typologies of language disorders are mostly based on symptomatic criteria. Nonetheless, they often fail to categorize and characterize patients unambiguously, essentially because of the widespread problems of comorbidity and heterogeneity. Likewise, they usually fail to incorporate etiological factors in a distinctive way, particularly, what we have learnt in the last decades about the genetic causes of neurodevelopmental conditions. Ultimately, these shortcomings are expected to impact negatively on therapies and the recovery of patient's abilities. This paper argues in favour of a systems biology approach to language disorders, which pays attention to the way in which the myriad of the biological factors involved (at the bottom) interact complexly to regulate language development and processing (at the surface). In particular, it argues for a classification of disorders based on intermediate-level components, like brain oscillations. This fresh approach to the etiopathogenesis of language disorders, which is more biologically motivated and more theoretically grounded, should allow identify robust endophenotypes of language disorders that can be used as reliable hallmarks for an earlier and more accurate diagnosis.

SUMmary: 1. Introduction. 2. Clinical linguistics: a messy scenario. 3. A paradigm shift in clinical linguistics. 4. Brain rhythms: bridging genes to language. 5. Conclusions and future prospects
EI justo medio: los trastornos del lenguaje desde la óptica de la biología de sistemas

RESUMEN: Las tipologías de los trastornos del lenguaje con los que trabaja la lingüística clínica se basan fundamentalmente en criterios sintomatológicos. No obstante, en muchas ocasiones dichas tipologías se muestran incapaces de categorizar adecuadamente a los pacientes y de caracterizar con precisión los problemas que presentan, fundamentalmente a causa de la heterogeneidad y la diversidad típicas de los trastornos, y de la comorbilidad que se advierte frecuentemente entre ellos. Asimismo, tales tipologías no contemplan como sería deseable la naturaleza de los factores etiológicos que explican en último término cada trastorno, y en particular, los de tipo genético. Una categorización y una caracterización inadecuadas de los pacientes conllevan indefectiblemente tratamientos menos precisos y, por tanto, menos eficaces. En este artículo se defiende la conveniencia de estudiar los trastornos del lenguaje desde la óptica de la biología de sistemas, con el objetivo último de discernir la manera en que todos los factores biológicos implicados interactúan de forma compleja para regular el desarrollo del lenguaje y su procesamiento a nivel cerebral. En concreto, se defenderá la pertinencia de una clasificación de los trastornos basada en componentes biológicos de nivel intermedio y en particular, en las oscilaciones cerebrales durante el procesamiento del lenguaje. Idealmente, esta nueva forma de abordar la etiopatogénesis de los trastornos, más justificada desde el punto de vista biológico y más coherente desde el punto de vista de la teoría evolutiva, debería permitir identificar endofenotipos más fiables, que puedan emplearse para un diagnóstico más exacto y más temprano de los trastornos.

SUMARIO: 1. Introducción. 2. Lingüística clínica: no todo está claro. 3. Hacia un cambio 
de paradigma en lingüística clínica. 4. Los ritmos cerebrales como puente entre los genes y el lenguaje. 5. Conclusiones y áreas de interés para la investigación futura. 


\section{The golden mean: A systems biology approach to language disorders}

ANTONIO BENÍTEZ-BURRACO

\section{INTRODUCTION}

This paper is aimed to discuss new theoretical approaches to the nature of language disorders that can account for many of the recent findings about their biological nature in the domains of genetics, brain physiology, or behaviour. Hopefully, these new models will help physicians, speech therapists, and clinical linguists to better interpret the relevance of these findings, improve their understanding of the aetiology and symptomatology of disorders, and ultimately, achieve earlier and more confident diagnoses of language disorders, as well as more efficient therapies. On paper, clinical categories like dyslexia or specific language impairment refer to cognitive disorders in which only language is impaired and that can be differentiated from other similar categories at all levels: linguistic, cognitive, neurobiological, and genetic. However, things are usually less clear-cut and more difficult to handle, essentially, because the boundaries between disorders are blurred at all those levels. This circumstance is expected to impact negatively on the diagnosis and the therapeutic approaches aimed to ameliorate the symptoms and deficits associated to these conditions. This problem is not easy to fix. The take-home lesson of the paper will be that clinical linguistics will benefit from a shift of focus in the line of the ongoing evo-devo revolution in biolinguistics, and more generally in biology: instead of relying on the analysis of the phenotype in the adult state, more attention should be paid to developmental dynamics in pathological populations across all levels of biological complexity, from genes to language deficits. Importantly, as discussed below, this should allow to find more reliable endophenotypes of these conditions, that is, disorder-specific biological markers of the disease. In the paper, brain oscillations will be highlighted as the most promising of such endophenotyes.

\section{CLINICAL LINGUISTICS: A MESSY SCENARIO}

As noted above, things for clinical linguists and speech therapists are not usually crystal-clear. To begin with, patients commonly show symptoms that are compatible with more than one disorder (linguistic or not linguistic by nature), to the extent that comorbidity is a frequent outcome of clinical practice. At the same time, people suffering from a particular disorder usually exhibit linguistic (dis)abilities that are pretty variable. In order to apprehend this variability different subtypes of the same disorder are usually posited, in which one aspect of language is claimed to be more impaired than others. Importantly, problems with language at the surface, so to speak, are only indirectly related to the cognitive deficits at the bottom. This seemingly contributes to increase the variability of the symptoms and makes the categorization of disorders more troublesome. On the whole, it seems that different disorders (or different subtypes of the same disorder) can emerge from the same (broad) cognitive deficit, which can appear differentially in different populations and/or environments. Hence the alleged heterogeneity and/or comorbidity. In other circumstances, however, different deficits (specific or not to language) can contribute to the same disorder, if they result in a common symptomatic profile. It is then possible that in each subtype of a particular disorder a different deficit prevails. At the same time, in other populations any of these underlying deficits can result in a different disorder. Hence the purported heterogeneity and/or comorbidity. Figure 1A summarises this complex scenario. 
A

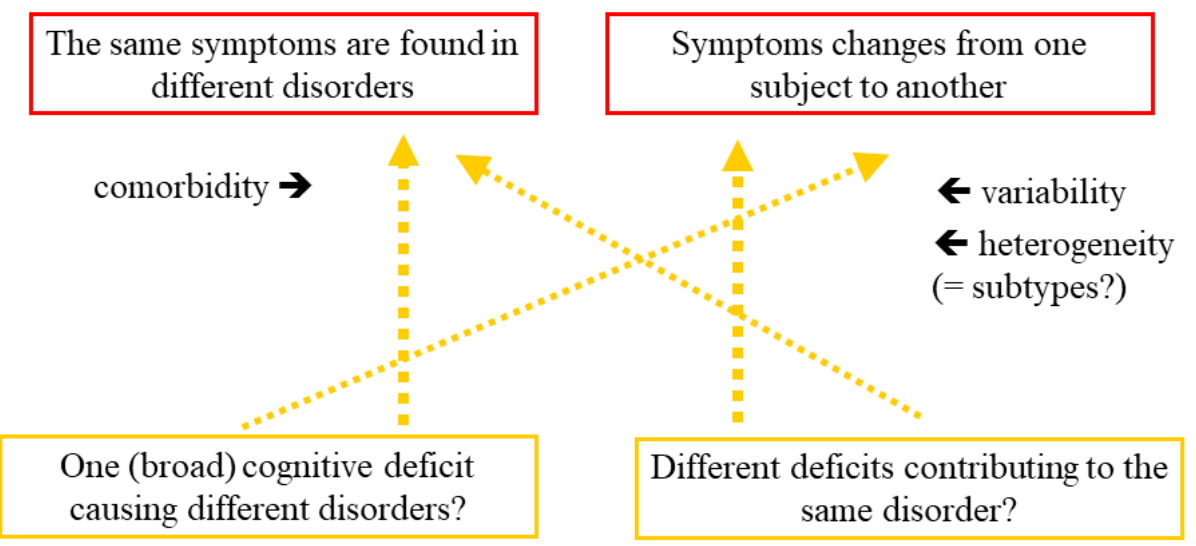

B

\begin{tabular}{|c|}
\hline $\begin{array}{c}\text { Problems concern to quite broad aspects } \\
\text { of language }\end{array}$ \\
\hline
\end{tabular}

relevant for linguistic theory? $\rightarrow$

What is impaired here?

Development is worth considering!

Figure 1. A MESSY SCENARIO FOR CLINICAL LINGUISTICS AT THE PHENOTYPICAL LEVEL. A. THE LINKS BETWEEN COGNITIVE DEFICITS AND LANGUAGE PROBLEMS IN LANGUAGE DISORDERS ARE NOT STRAIGHT OR UNIVOCAL. B. THE LINKS BETWEEN LANGUAGE PROBLEMS AND ASPECTS OF THE GRAMMAR ARE NOT STRAIGHT EITHER AND CHANGE THOROUGH DEVELOPMENT.

Another important concern is that, very frequently, problems with language in the affected people concern to quite broad aspects of language, to the extent that they do not match units, levels, features, or operations that are important for modern linguistic theory (Figure 1B, left). As a consequence, clinical typologies are sometimes weird for linguists. For instance, according to some accounts (e.g. Rapin and Allen, 1983) there exists a syntactic-pragmatic subtype of specific-language impairment. But linguists carefully differentiate between the knowledge of a language (the grammar) and how this knowledge is put into use (pragmatics). Actually, for most linguists (and for most neurolinguists indeed) pragmatics involves many other things besides our linguistic competence.

Finally, consider that the clinical profile of the patients usually changes throughout development, to the extent that the affected subjects can switch from one subtype to another of the same disorder as they grow (Figure 1B, right). Accordingly, one cannot simply assume that deficits in the adult state are the same as those apparent in the infant state (and vice versa).

Comorbidity, heterogeneity, and variability are observed at the neurobiological level too (Figure 2). Accordingly, the brain areas found affected in one disorder can be found impaired in people suffering from a different disorder. Moreover, it is frequently observed that the affected regions give rise to mixed symptoms. Overall, it is not clear whether the involved regions are multifunctional by nature or perform instead some basic computations that are recruited for language and for other cognitive abilities. Lastly, it commonly happens that the limits of the affected areas are differently placed in different subjects. 


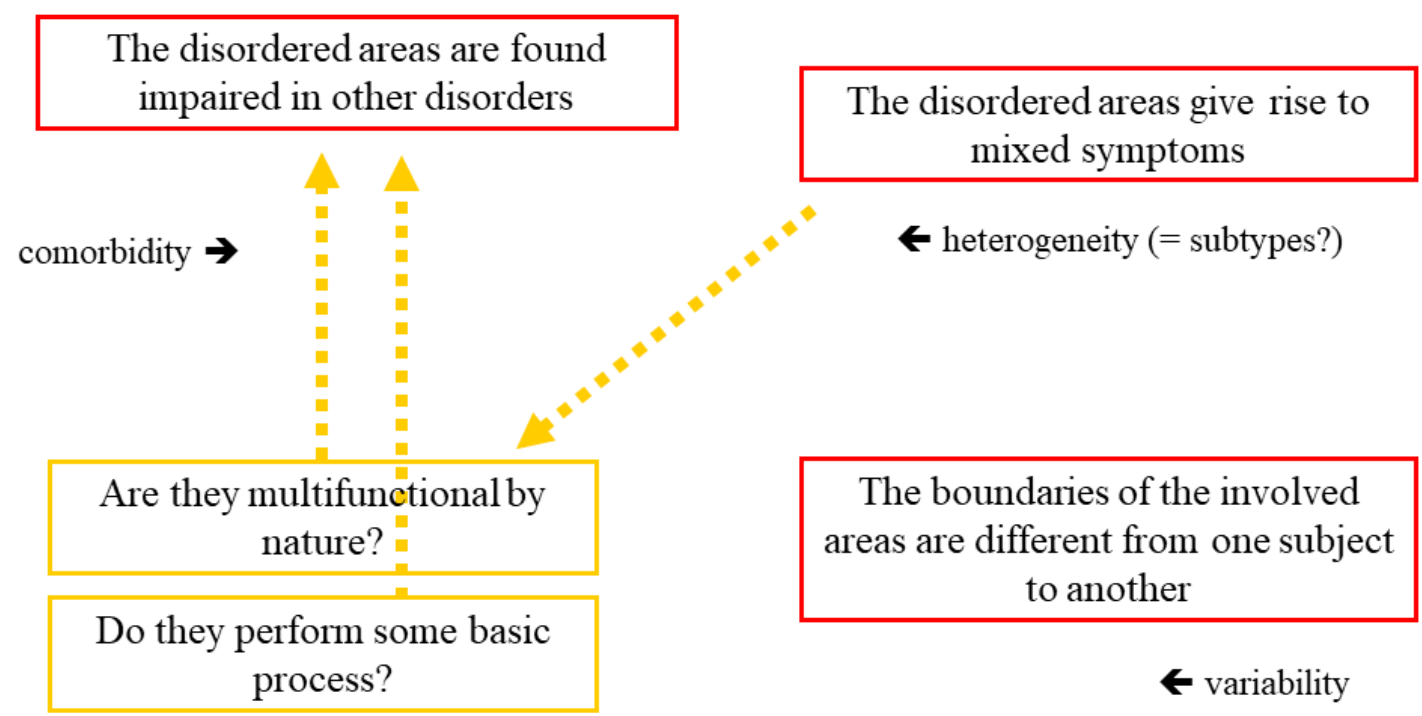

Figure 2. A MESSY SCENARIO FOR CLINICAL LINGUISTICS AT THE NEUROBIOLOGICAL LEVEL.

Things are not easier to interpret at the molecular level. Different candidate genes and risk factors for different language disorders have been identified to date. However, it is not one but many genes that usually contribute to each disorder. Typically, several pathogenic variants of each candidate gene have been found. At the same time, other variants of the same gene have been proved to contribute to the language abilities of the neurotypical population. Importantly, the same mutation in the same gene can cause the disorder in some individuals, but not in others. Conversely, pathogenic variants of a particular candidate gene are frequently absent in people affected by the disorder. What is more, the same mutation in the same gene can give rise to different disorders in different subjects, to the extent that candidate genes for a particular disorder are frequently mentioned as candidates for several other clinical conditions. Finally, it is frequently observed that mutations in genes encoding proteins that are functionally related (if, for instance, one regulates the expression of the gene encoding the other) can give rise to different disorders in different people and/or environments (Table $1)$.

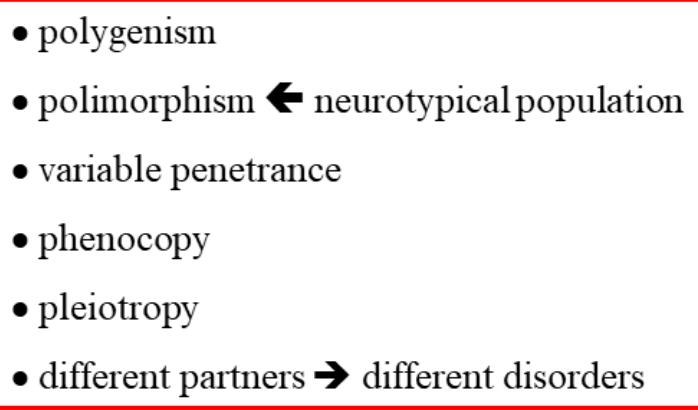

Table 1. A MESSY SCENARIO FOR CLINICAL LINGUISTICS AT THE GENETIC LEVEL

The advent of the so-called "-omics revolution" in Biology has turned this complex scenario even more complex. On the one hand, the amount of biological data about disorders has grown exponentially. On the other hand, we have learnt that there are additional levels of complexity that have to be explored if we really want to gain an accurate picture of the real nature of disorders. Accordingly, epigenetic changes, modifications of protein networks, alterations of signalling pathways, abnormal patterns of neuronal assembly, or aberrant patterns of neuronal synchronization need to be consider on a par to gene mutations, abnormal neuroimaging results, or language deficits (Figure 3). Importantly, as we will try to show in the last part of this paper when discussing about 
brain oscillations, it might well be that the specificity of language in cognition, and hence, the idiosyncrasy of language disorders, that we have been unable to find at the genetic or the phenotypical levels, can be found instead at some of these new levels of biological complexity.

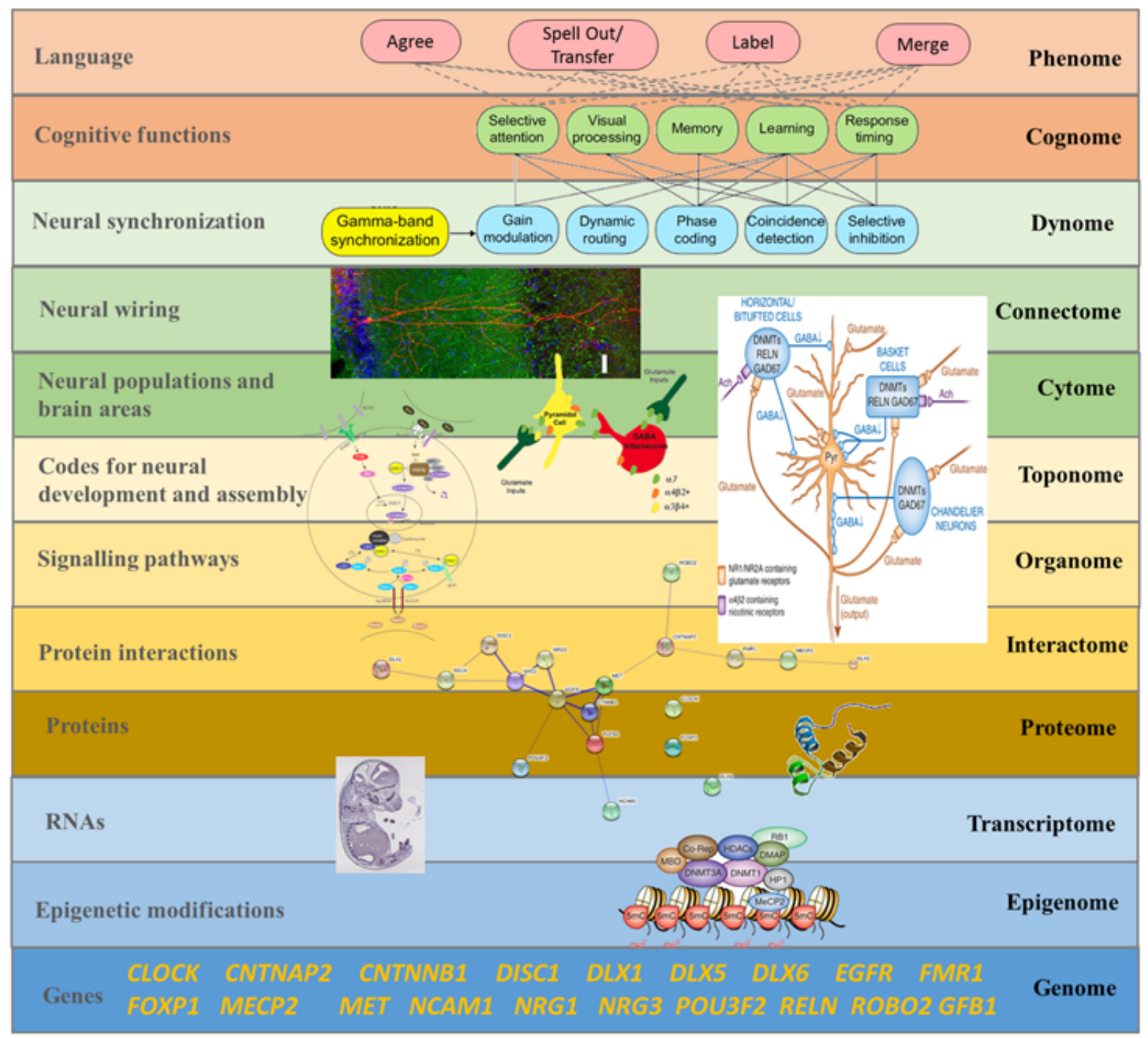

Figure 3. LEVELS OF BIOLOGICAL COMPLEXITY THAT HAVE TO BE CONSIDERED IN ANY COMPREHENSIVE CHARACTERIZATION OF LANGUAGE (AND OF LANGUAGE DISORDERS) FROM A BIOLOGICAL PERSPECTIVE (modified from Benítez-Burraco and Murphy, 2014; figure 4).

\section{A PARADIGM SHIFT IN CLINICAL LINGUISTICS}

If we summarize what we have discussed in the last section, it seems that clinical linguistics, which has traditionally focused on the cognitive and linguistic evaluation of patients and the analysis of corpora of disordered language, faces today a triple challenge. First, it needs to consider new types of evidence, as provided by many different areas of research interested in language disorders (this is the challenge of multidisciplinarity). Second, it needs to incorporate new methodologies and tools, which are often complicate to understand and use (this is the challenge of technification). Third, it needs to formulate new models of language disorders that take into account this increasing body of data about the biology of language disorders, but particularly, fresh models of development and evolution as currently discussed in biological sciences (this is the challenge of theorization). In this paper the focus is put on this last challenge.

In truth, one possible (and perhaps the only possible) way of addressing these three challenges is adopting a systems biology approach to language disorders. Contrary to other approaches to 
biological facts, which are reductionists by nature, systems biology is aimed to study the dynamics of cellular and organismal function, with a focus on properties of the whole system (Kitano, 2002). Systems biology as adapted to clinical linguistics would be aimed to characterise, from a holistic perspective, the complex interactions among myriads of biological components that take place within the brain of people with disorders when processing language, as well as the emergent properties resulting from such interactions. Among other things, this fresh approach is expected to circumvent the caveats and shortcomings of current typologies of language disorders, which are mostly based on symptomatic criteria or on aetiological criteria. Typologies based on symptoms often fail to categorize and characterize patients unambiguously, essentially because of the widespread problem of comorbidity and heterogeneity, discussed above. Also, they usually fail to incorporate etiological factors in a disorder-specific way, particularly, what we have learnt in the last decades about the genetic causes of neurodevelopmental conditions. For instance, as far as genes are concerned, it seems now that language disorders do not result from the alteration of one or a few disorder-specific genes, but of many if not most of the genes expressed in the brain (Boyle et al., 2017). Accordingly, it seems better and more biologically-sounded to characterise each disorder in terms of whole-brain transcriptomic profiles, that we expect to be of disorder-specific. But this could be not enough, considering that aetiological classifications of disorders usually fail to incorporate many of the other involved factors, like epigenetic factors. More importantly, they also fail to explain why only a bunch of distinctive symptomatic profiles result from the interaction of thousands of potential etiological factors, some of them altered and some of them intact, with most, if not all, of these pieces being shared across disorders that exhibit different symptomatic profiles.

Actually, this messy scenario (as we called it in the previous section of the paper) is easier to interpret if we rely on eco-evo-devo theories in biology, which build on the deep link between the environment, development, and evolution. According to this approach, language evolved as a result of specific changes in the developmental path of the hominin brain in response to changes in the environment in which our ancestors lived (see Benítez-Burraco and Coblijn, 2015 for a review). And it is the most recently evolved components of human cognition which are expected to be the most sensitive to the deleterious effect of developmental perturbations resulting from environmental changes, either internal to the organism or external to it. This circumstance seemingly explains as well two widespread outcomes of clinical linguistics. First, although, as noted, the aetiology of disorders is quite diverse, some deficits are shared by nearly all conditions and they usually concern to morpho-phonology and to highly demanding computational tasks like agreement. Second, although, as also noted, the number of etiological factors is high, the number of disorders is far smaller. Regarding the first finding, language evolution can be also viewed as the emergence of new interfaces between basic cognitive blocks that are otherwise very robust after millions of years of stabilizing selection and that, as a consequence, are not usually found impaired in disorders. By contrast, because of their evolutionary novelty, and ultimately because the less resilience of the networks they rely on, these new interfaces are more sensitive to damage. Regarding the second finding, the disorders that are finally attested by clinical linguistics might be the only possible set of phenotypes resulting from the interaction of the diverse factors, normal or abnormal, that regulate the development of the brain. In eco-evo-devo theories the limited set of phenotypes available during development are construed as definite areas within a morphospace or adaptive landscape (Arnold et al., 2001; Erwin, 2017). Putting it differently, developmental dynamics canalizes development towards a restricted set of ontogenetic paths. Accordingly, what we call the neurotypical language brain might be viewed as the outcome of a successful canalization of the otherwise widespread developmental noise (e.g. gene mutations, minor brain anomalies, and the like). In turn, what we call language disorders can be viewed as suboptimal canalizations of more severe developmental disturbances (e.g. deleterious gene mutations, brain damage, etc.).

What we need to determine are the optimal parameters defining the language morphospace. Consider, as a good example, the shells of ammonites and nautili. Similarly to language disorders, the number of different shell forms was small: coiled, uncoiled, and helical. Nonetheless, the shell morphology depended on two parameters, rib expansion rate and rib coiling tightness, which changes 
continuously, similarly to what happens with the aetiological factors of disorders (Moulton et al., 2015). As far as language disorders as concerned, one possibility might be relying on (aberrant) gene expression profiles in the brain, with the aim of characterizing, at the molecular level, the diverse states attracted through development: whereas some expression profiles would characterize language disorders, other or perhaps several ones would be typically associated to the intact faculty of language. Nonetheless, in the last section of the paper, we will highlight one intermediate-level component, namely, brain rhythms as a better (or perhaps, the optimum) candidate for properly defining the morphospace of language growth in the species, either pathological or neurotypical.

\section{BRAIN RHYTHMS: BRIDGING GENES TO LANGUAGE}

Several reasons justify our current interest in brain oscillations. First, they are primitive components of brain function. Second, we expect them to be connected to some computational primitives of language, thus allowing to understand (and not only to localize) brain functions. As famously noted by David Poeppel (Poeppel and Embick, 2005), current neurolinguistic studies suffer from two crucial shortcomings. On the one hand, they make too broad conceptual distinctions (syntax vs. semantics, morphology vs. syntax, etc.), which involve multiple neural components, computations, and representations. On the other hand, the core elements of linguistic theory do not match the core biological elements identified by neuroscience. It is then urgent to spell language in computational terms that can be processed by specific parts of the brain in real time. We regard brain rhythmicity one (and perhaps the most suitable) of these appropriate levels of abstraction. For example, as shown in Figure 4, the assignment of language-relevant features, like Tense and Case, can be satisfactorily interpreted as the embedding of high frequency oscillations inside oscillations operating at a slower frequency. Similarly, some rhythmic features of speech have been successfully related to specific brain oscillations (e.g. Meyer, 2017 among many others). A third reason is that the hierarchy of brain oscillations has remained remarkably preserved within mammals during evolution. Not surprisingly, the human-specific pattern of brain activity underlying language processing can be evolutionary linked to the oscillatory signature of the primate brain. Specifically, the emergence of the human language oscillome (that is, the language-related phasal and cross-frequency coupling properties of neural oscillations) seemingly re-shaped the ancient primate oscillome we inherited, although the reverse also happened: this why we found in human languages that semantics imposes particular constraints on possible syntactic structures (Murphy, 2016). A final, but very important reason is that each cognitive disorder can be associated to specific profiles of brain rhythmicity. This is of particular interest for clinical linguistics: because brain rhythms are highly quantifiable and heritable traits, they might result in robust biomarkers or endophenotypes of language disorders. For example, gamma band dysfunction has been hypothesised to be a robust biomarker of autism spectrum disorders (Port et al., 2015).

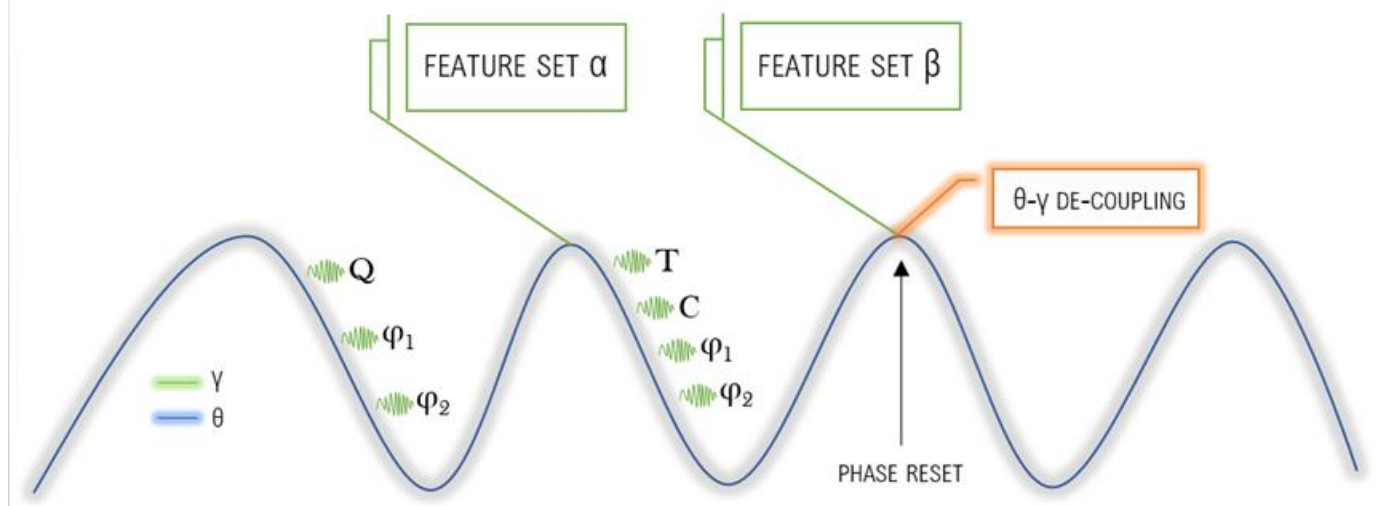

Figure 4. AN IDEALISED SCHEMA SHOWING THE LINKS BETWEEN SOME LANGUAGE-RELEVANT FEATURES AND SPECIFIC BRAIN RHYTHMS (from Murphy and Benítez-Burraco, 2017; figure 2) 
Nonetheless, if we really want to use these oscillopathic profiles as reliable biomarkers or endophenotypes of language disorders, we first need to map these abnormal disorder-specific patterns of brain oscillation to the language deficits that are also typical of each disorder. Pretty obviously, this translational effort should also allow to gain a better understanding of the nature of the disorders and consequently, the aetiology of the language deficits associated to each condition, particularly, of the effect of gene mutations. Fortunately, this translational effort has proven to be feasible. Accordingly, language deficits observed in conditions like autism spectrum disorders (ASD), schizophrenia, or dyslexia, can be explained in terms of aberrant changes in the normal oscillatory activity of the brain (Benítez-Burraco and Murphy, 2016; Murphy and Benítez-Burraco, 2016; Jiménez-Bravo et al., 2017, respectively). For example, when processing speech, $\gamma$ oscillations correspond to phonetic features and are important as well for accessing stored templates from memory. As a consequence, degraded $\gamma$ and $\theta$ synergy in ASD may explain the problems that people with this condition experience with speech perception, tone recognition, and parsing phonemic representations.

Even more importantly, some candidate genes for these conditions can be confidently associated to specific brain rhythms. In some cases, it is even possible to draw bridging links between all the involved levels of biological complexity, from gene mutations to abnormal brain oscillations to language deficits (see Murphy and Benítez-Burraco, 2018a). For example, as shown in Figure 5, ZNF804A encodes a zinc finger binding protein and is highly expressed in the hippocampus and the neorcortex, particularly during late embryonic development. The hippocampus is a source of $\theta$ bands, which play a major role in coordinating distributed cross-cortical activity (in particular, activity in the prefrontal cortex). Because of their involvement in working memory as a filter that imposes memory-related rules, and because of the overall role of the hippocampus in the transformation of individual experiences into semantic structures such as maps and schemas, hippocampal $\theta$ are expected to explain core aspects of language processing, both syntactic (like the "chunking" of syntactic objects) and semantic (like category fluency). Pathogenic polymorphisms of the gene have been related to semantic problems in subjects with schizophrenia. Accordingly, significant decreases in the coactivation of the right hippocampus within the whole hippocampal network, as well as in intrahippocampal $\theta$ band, have been found in risk homozygotes for one variant of the gene. Interestingly, people with this risk allele show a greater coactivation of the hippocampus and the prefrontal cortex (specifically, the superior frontal gyrus). Likewise, several polymorphisms of the gene have been associated to verbal deficits in people with ASD, who exhibit a reduced expression of $Z N F 804 A$ in several brain areas, like the anterior cingulate gyrus. 


\section{Category fluency}

\section{Semantic processing}

\section{Schizophrenia}

\section{Working memory}

$\mathbf{a}$

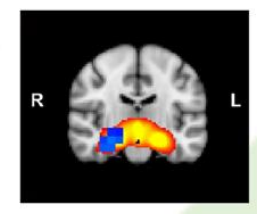

b
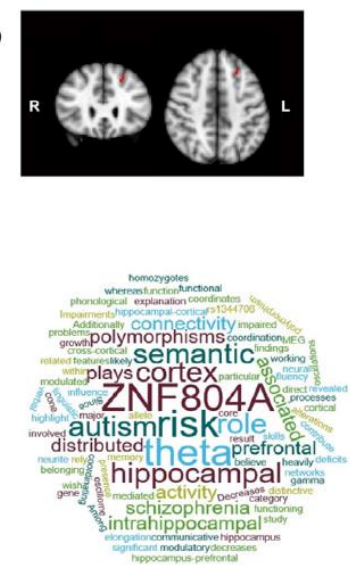
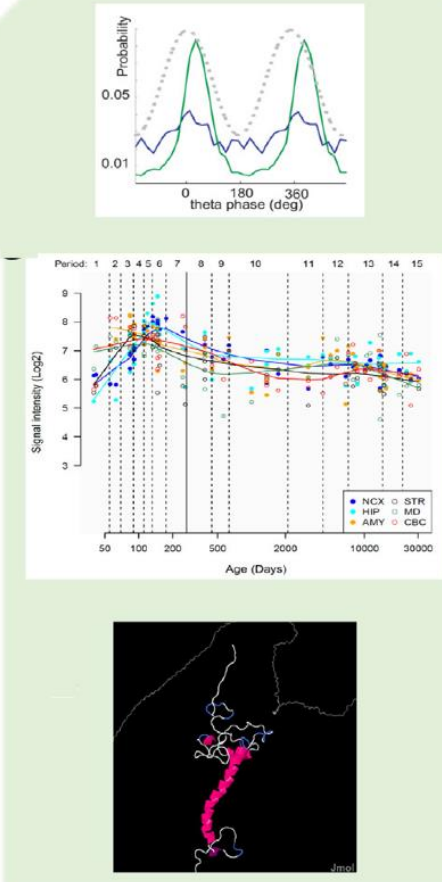

Autism

$\mathbf{a}$

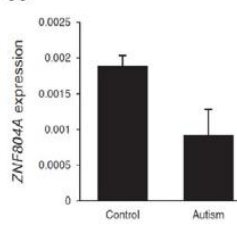

b

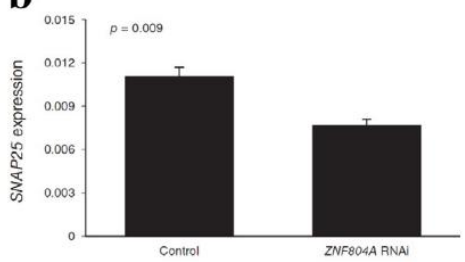

Figure 5. THE MOTIVATED LINKS BETWEEN ZNF804A, BRAIN OSCILLATIONS, AND LANGUAGE DEFICITS IN ASD AND SCHIZOPHRENIA (from Murphy and BenítezBurraco, 2017; figure 4)

Just to put another example, as illustrated by Figure 6, GRIN2A is a gene that encodes the subunit 2A of the N-methyl-D-aspartate (NMDA) receptor, which plays a key role in long-term potentiation, important for memory formation and learning. This function seemingly results in part from its regulation of $\gamma$ oscillation formation and modulation. Mutations in GRIN2A are found in people suffering from different forms of epilepsy-aphasias (like rolandic epilepsies or LandauKleffner syndrome). Specifically, they are associated with errors in articulation and with problems with pitch and prosody, which pertain to the syntax-phonology interface. In turn, these deficits can be tracked to an abnormal $\gamma$ activity, involved in the processing of fast-rate phonemic and syllabic information. 


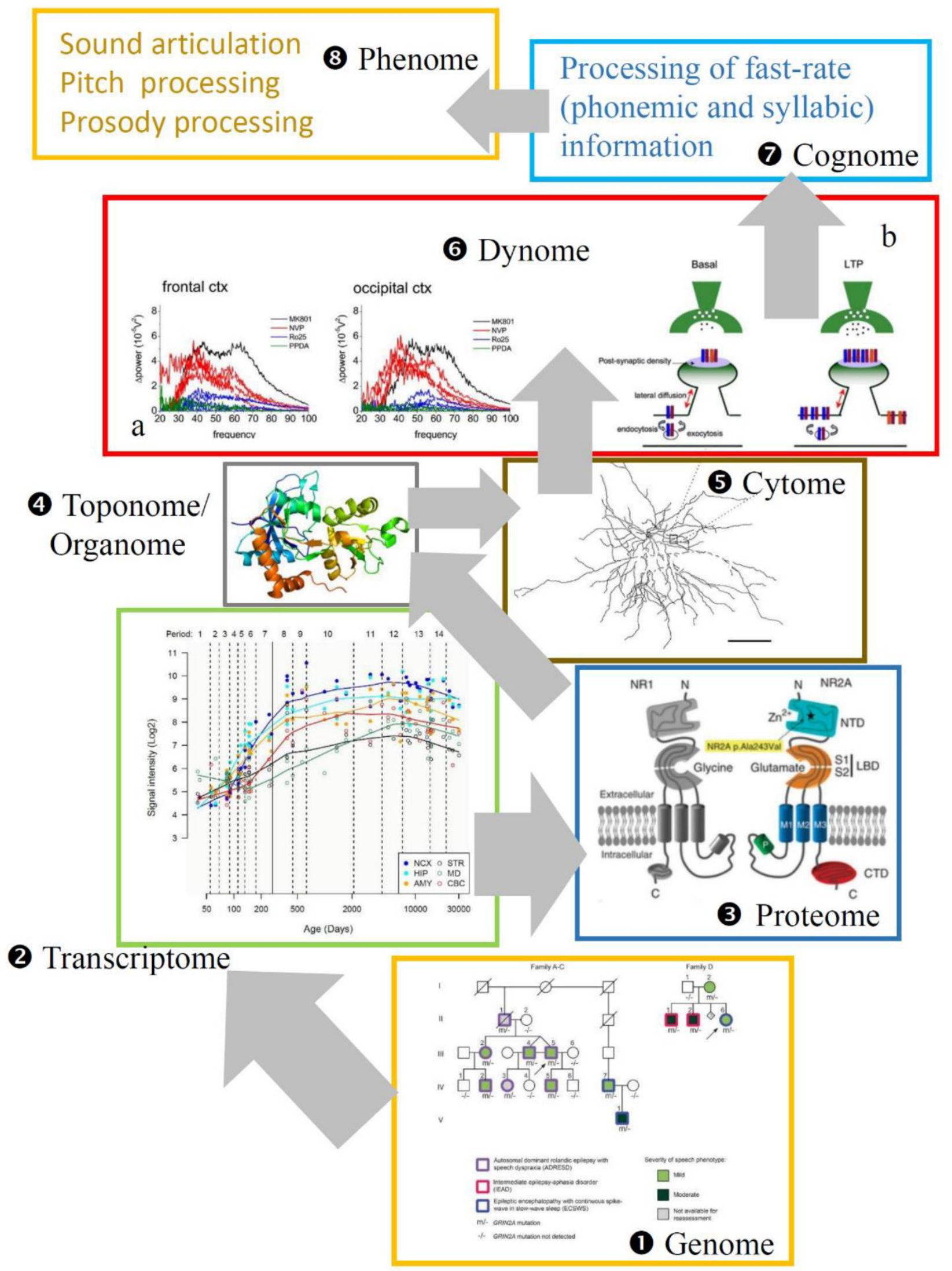

Figure 6. THE MOTIVATED LINKS BETWEEN GRIN2A, BRAIN OSCILLATIONS, AND LANGUAGE DEFICITS IN SCHIZOPHRENIA AND EPILEPSIES

Interestingly, most of these candidates for language disorders that play a role in brain rhythmicity are functionally interrelated and map on particular regulatory pathways, cell types or 
functions, as well as facets of brain development and function, of relevance for language processing, particularly through dopaminergic, GABAergic and glutamatergic synapses. Importantly too, they exhibit a distinctive, disorder-specific pattern of up and downregulation in the brain of patients, which contributes to bridge genes to oscillations to language features. Notice that the specificity of the molecular signature of each disorder relies not on the set of genes involved, which are essentially the same, but on their expression patterns in each brain region, which is different in each condition.

Finally, and perhaps not surprisingly, it is important to note that several of these genes responsible for basic aspects of the oscillatory activity of the brain relevant for language show differences in their methylation status between Neanderthals and humans (Murphy and BenítezBurraco, 2018b). We cannot track the oscillatory activity of the brain of extinct hominins, but, as showed before, from these molecular differences that are suggestive of differences in the expression pattern of these genes, we can infer differences in cognitive functions important for language. In summary, because of this bridging role between the genes (at the bottom) and language features (at the surface), both developmentally and evolutionarily, brain rhythms could be the biological level at which the specificity of each disorder emerges... the golden mean, just to say.

\section{CONCLUSIONS AND FUTURE PROSPECTS}

Decades of research on child language, either neurotypical or impaired, have demonstrated that language development is heavily influenced by external factors, that can contribute very significantly to the emergence of language disorders. This is another reason why a systems biology approach to language disorders (or an eco-evo-devo clinical linguistics, which is quite the same) is worth pursuing. Systems biology construes organisms as open systems in close contact with the environment and has implemented the tools for properly capturing the effect of these interactions on development (this can be viewed as the eco side of eco-evo-devo). To put just one example. Our microbiota (and more generally, the gut-brain cross-talk) has been found to control important aspects of brain development and function. Increasing evidence suggests that alterations of the gut-microbiota axis can disturb some of the cognitive networks encompassing emotional and social domains in neurodevelopmental disorders, and accordingly, contribute to the social and emotional deficits observed in conditions like ASD and schizophrenia. Although mechanistic insights are still pending, it is clear now that a systems level dimensional approach to this issue can result in findings of clinical relevance. The same can be said, specifically, of language disorders. This is not surprising, after all, because the environment has an impact on all the levels of biological complexity related to language impairment... including brain oscillations, of course. Accordingly, we should expect a connection between environmental cues, abnormal brain development, altered brain oscillations, and language deficits.

It is pretty obvious that this research has a practical side too. If we succeed in this translation of language dysfunctions into disorder-specific patterns of brain anomalous oscillations, we might be able to diagnose language disorders earlier and in more accurate ways. Several complementary lines of future research are of particular interest for improving this systems biology (or eco-evo-devo) approach to language disorders that heavily builds on brain rhythms. First, we need to disentangle the molecular mechanisms that channel (and fail to channel) variation at all levels of biological complexity. Second, we need to improve eco-evo-devo-friendly depictions of the modularization of the disordered brain. Third, we should optimize our current models of the linguistic ontogeny in people with disorders. Finally, we should pay attention to emergent properties (and to properties that fail to emerge), because language is undoubtedly a complex system and many of the properties of complex systems are emergent by nature.

In summary, characterizations and classifications of language disorders based on intermediate-level components (particularly, on the coupling between brain oscillations during language processing) are more biologically motivated and more theoretically grounded than others (particularly, the ones currently used by clinical linguists, either symptoms or causes). Accordingly, they are expected to help us identify more robust endophenotypes of language disorders that can be used as reliable hallmarks for an earlier and more accurate diagnosis of these conditions. 


\section{ACKNOWLEDGMENTS}

This work was supported by funds from the Spanish Ministry of Economy and Competitiveness (grant number FFI2016-78034-C2-2-P [AEI/FEDER,UE] to Antonio Benítez-Burraco.

\section{REFERENCES}

Arnold, S. J., Pfrender, M. E., and Jones, A. G. (2001): "The adaptive landscape as a conceptual bridge between micro- and macroevolution", Genetica, 112-113, pp. 9-32.

Benítez-Burraco, A., and Murphy, E. (2016) "The oscillopatic nature of language deficits in autism: from genes to language evolution”. Frontiers in Human Neuroscience, 10, 120.

Boyle, E. A. Li, Y. I., and Pritchard, J. K. (2017): "An expanded view of complex traits: from polygenic to omnigenic", Cell, 169, pp. 1177-1186.

Erwin, D. H. (2017): "The topology of evolutionary novelty and innovation in macroevolution", Philosophical Transactions of the Royal Society B: Biological Sciences, 372, 20160422.

Jiménez-Bravo, M., Marrero, V., and Benítez-Burraco, A. (2017): "An oscillopathic approach to developmental dyslexia: from genes to speech processing”, Behavioural Brain Research, 329, pp. 8495.

Kitano, H. (2002): “Computational systems biology”, Nature, 420, pp. 206-210.

Meyer, L. (2017): “The neural oscillations of speech processing and language comprehension: state of the art and emerging mechanisms", European Journal of Neuroscience, doi: 10.1111/ejn.13748.

Moulton, D. E., Goriely, A., and Chirat, R. (2015): “The morpho-mechanical basis of ammonite form”. Journal of Theoretical Biology, 364, pp. 220-230

Murphy, E. (2016): "Evolutionary monkey oscillomics: generating linking hypotheses from preserved brain rhythms". Theoretical Linguistics, 42, pp. 117-137

Murphy, E. and Benítez-Burraco, A. (2016) "Bridging the gap between genes and language deficits in schizophrenia: an oscillopathic approach". Frontiers in Human Neuroscience, 10, 422.

Murphy, E. and Benítez-Burraco, A. (2017): "Language deficits in schizophrenia and autism as related oscillatory connectomophathies: an evolutionary account". Neuroscience \& Biobehavioral Reviews, 83, pp: 742-764.

Murphy, E. and Benítez-Burraco, A. (2018a): "Towards the language oscillogenome", Frontiers in Psychology doi: 10.3389/fpsyg.2018.01999

Murphy, E. and Benítez-Burraco, A. (2018b): Paleo-oscillomics: reconstructing language-relevant computational capacities in Neanderthals from the molecular basis of neural oscillations. Journal of Anthropological Sciences 
Poeppel, D. and Embick, D. (2005): "Defining the relation between linguistics and neuroscience", Cutler, A. (ed.): Twenty-first Century Psycholinguistics: Four Cornerstones, Hillsdale: Lawrence Erlbaum, pp. 103-120.

Port, R. G., Anwar, A. R., Ku, M., Carlson, G. C., Siegel, S. J., and Roberts, T. P. (2015): "Prospective MEG biomarkers in ASD: pre-clinical evidence and clinical promise of electrophysiological signatures", Yale Journal of Biological Medicine, 88, 25-36.

Rapin, I. and Allen, D. A. (1983): "Developmental language disorders: nosologic considerations", in Kirk, U. (ed.), Neuropsychology of Language, Reading and Spelling, New York: Academic Press, pp. $155-184$ 